\title{
Correlation between Quantumchemically Calculated LUMO Energies and the Electrochemical Window of Ionic Liquids with Reduction-Resistant Anions
}

\author{
Wim Buijs, ${ }^{1}$ Geert-Jan Witkamp, ${ }^{1}$ and Maaike C. Kroon ${ }^{2}$ \\ ${ }^{1}$ Laboratory for Process Equipment, Department of Process \& Energy, Faculty of Mechanical, Maritime and Materials Engineering, \\ Delft University of Technology, Leeghwaterstraat 44, 2628 CA Delft, The Netherlands \\ ${ }^{2}$ Separation Technology Group, Department of Chemical Engineering and Chemistry, Eindhoven University of Technology, \\ Den Dolech 2, 5612 AZ, P.O. Box 513, STO 1.22, 5600 MB Eindhoven, The Netherlands \\ Correspondence should be addressed to Wim Buijs, w.buijs@tudelft.nl
}

Received 29 January 2012; Accepted 7 March 2012

Academic Editor: Sherif Zein El Abedin

Copyright (๑) 2012 Wim Buijs et al. This is an open access article distributed under the Creative Commons Attribution License, which permits unrestricted use, distribution, and reproduction in any medium, provided the original work is properly cited.

Quantum chemical calculations showed to be an excellent method to predict the electrochemical window of ionic liquids with reduction-resistant anions. A good correlation between the LUMO energy and the electrochemical window is observed. Surprisingly simple but very fast semiempirical calculations are in full record with density functional theory calculations and are a very attractive tool in the design and optimization of ionic liquids for specific purposes.

\section{Introduction}

In the last two decades ionic liquids [1-3] have received much interest for use as water-free electrolytes. They might combine the advantages of the conventional high-temperature molten salt electrolytes and aqueous electrolytes. Ionic liquids have wide electrochemical [4-6] and temperature $[1,2]$ windows, high ionic conductivities [6, 7], can dissolve most metal salts [1-3], and allow several metals conventionally obtained from high-temperature molten salts to be deposited at room temperature without corrosion problems [8-11]. Moreover, they might posses lower toxicity, flammability, and volatility compared to conventional electrolyte systems [12]. Applications include the use of ionic liquids as electrolytes in battery systems [13], solar cells [14], and electrochemical capacitors [15-17]. In principle, it is possible to tune the properties of ionic liquids [2]. However, taskspecific design of ionic liquids is not straightforward. Reasons for that are that the synthesis of a large variety of ionic liquids is still cumbersome, and experimental measurements on the properties of ionic liquids are relatively scarce. Molecular modeling can be a useful tool to establish both qualitative and quantitative relations between the properties of ionic liquids and their structure [18].
In this work quantum chemical calculations are used to predict the electrochemical stability of ionic liquids with reduction-resistant anions. The electrochemical window [1] of such ionic liquids depends primarily on the resistance of the cation against reduction and the resistance of the anion against oxidation [12]. Previously, Koch et al. have correlated the electrochemical oxidation potentials of several anions with their respective highest occupied molecular orbital (HOMO) energies [19], and an excellent fit was obtained. In this study the electrochemical stability of a series of ionic liquids is correlated with the energy levels of the lowest unoccupied molecular orbital (LUMO) of the cations.

\section{Experimental}

All calculations were carried out using the Spartan'10 molecular modeling suite of programs [20]. Of all ionic liquid structures built, the best conformer was selected using molecular mechanics. These conformers were fully geometry optimized at the B3LYP level using the corresponding PM3 structures as input.

The underlying assumptions are that major properties of an ionic liquid can be obtained from just a single cation/ anion pair or in several cases even from the single cation 
TABLE 1: $E_{\mathrm{LUMO}}$ of several ionic liquids and $E_{\mathrm{LUMO}}$ of the cations only (calculated at PM3 level).

\begin{tabular}{lcc}
\hline Ionic liquid & $E_{\mathrm{LUMO}}$ (ionic liquid) [eV] & $E_{\mathrm{LUMO}}(\mathrm{cation})[\mathrm{eV}]$ \\
\hline 1-butylpyridinium tetrafluoroborate & -2.31 & -5.78 \\
1-butyl-3-methylimidazolium tetrafluoroborate & -1.39 & -4.95 \\
1-butyl-2,3-dimethylimidazolium tetrafluoroborate & -1.46 & -4.84 \\
1,1-butylmethylpyrrolidinium tetrafluoroborate & -0.63 & -4.21 \\
\hline
\end{tabular}

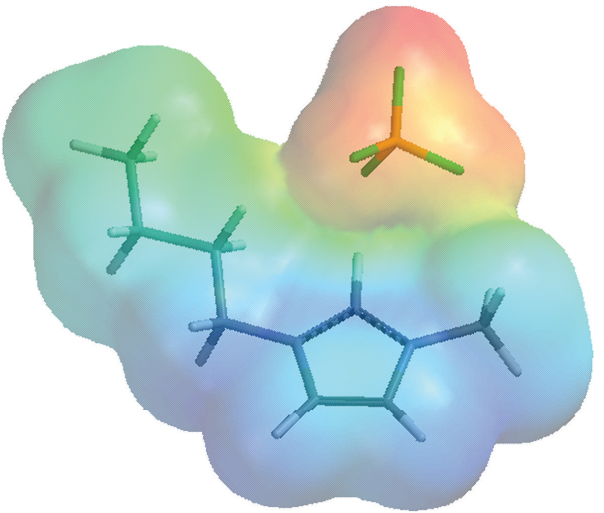

FIGURE 1: Structure of $\left[\mathrm{bmim}^{+}\right]\left[\mathrm{BF}_{4}^{-}\right]$showing the electrostatic potential projected on the van der Waals surface (surface $=$ electron density of $0.002 \mathrm{e} / \mathrm{au}^{3}$, property = electrostatic potential). The electron density is high under the red positions and low under the blue positions, indicative for negative and positive parts of the molecular ensemble.

or anion. Furthermore the application of HOMO/LUMO theory for electrochemical oxidation/reduction reactions assumes that there is no specific anodic/cathodic interaction with the anion/cation of the ionic liquid or internal reaction between the cation and the anion and that the electrochemical reactions can be described as outer sphere electron transfer processes, obeying the Franck-Condon principle [21].

\section{Results and Discussion}

The structure of the ionic liquid 1-butyl-3-methylimidazolium tetrafluoroborate $\left(\left[\mathrm{bmim}^{+}\right]\left[\mathrm{BF}_{4}^{-}\right]\right)$was calculated at B3LYP level. It shows nonbonded interactions $(\mathrm{C}-\mathrm{H} \cdot \cdots \mathrm{F}$ hydrogen bonds) between the $\mathrm{BF}_{4}{ }^{-}$and (i) the hydrogen at ring position $\mathrm{C} 2$ and (ii) a methyl group hydrogen as can be seen in Figure 1.

The electrostatic potential map indicates that the negative charge (red colored) is located on the formal anion $\left(\mathrm{BF}_{4}^{-}\right)$and the positive charge (blue colored) on the formal cation $\left(\mathrm{bmim}^{+}\right)$. The structure is nearly identical to previous calculations $[22,23]$. Thereafter, the position of the LUMO on $\left[\mathrm{bmim}^{+}\right]\left[\mathrm{BF}_{4}^{-}\right]$was determined. This position was compared to the position of the LUMO on the cation only as shown in Figure 2. From Figure 2 it can be concluded that the LUMO of this ionic liquid is totally located on the cation.

Because the LUMO is located completely on the cation, the resistance of the cation against reduction determines the stability with respect to reduction of the ionic liquid predominantly. However, because of obvious interactions
TABLE 2: Calculated LUMO energies (B3LYP) for several cations.

\begin{tabular}{|c|c|c|}
\hline Cation & & $\begin{array}{c}E_{\mathrm{LUMO}} \\
(\mathrm{B} 3 \mathrm{LYP})[\mathrm{eV}]\end{array}$ \\
\hline 1-butylpyridinium & {$\left[\right.$ bpyrid $\left.^{+}\right]$} & -6.46 \\
\hline 1-butyl-2-methylpyrazolium & {$\left[\right.$ bmpyraz $\left.^{+}\right]$} & -5.28 \\
\hline 1-ethyl-3-methylimidazolium & {$\left[\mathrm{emim}^{+}\right]$} & -4.92 \\
\hline 1-butyl-3-methylimidazolium & {$\left[\mathrm{bmim}^{+}\right]$} & -4.82 \\
\hline 1-octyl-3-methylimidazolium & {$\left[\mathrm{omim}^{+}\right]$} & -4.80 \\
\hline 1-ethyl-2,3-dimethylimidazolium & {$\left[\operatorname{edmim}^{+}\right]$} & -4.65 \\
\hline 1-butyl-2,3-dimethylimidazolium & {$\left[\mathrm{bdmim}^{+}\right]$} & -4.54 \\
\hline 1-octyl-2,3-dimethylimidazolium & {$\left[\operatorname{odmim}^{+}\right]$} & -4.51 \\
\hline trimethylpropylammonium & {$\left[\mathrm{N}(1113)^{+}\right]$} & -3.22 \\
\hline trimethylhexylammonium & {$\left[\mathrm{N}(1116)^{+}\right]$} & -3.13 \\
\hline trimethylpropylphosphonium & {$\left[\mathrm{P}(1113)^{+}\right]$} & -2.95 \\
\hline trimethylhexylphosphonium & {$\left[\mathrm{P}(1116)^{+}\right]$} & -2.85 \\
\hline 1,1-ethylmethylpyrrolidinium & {$\left[\right.$ empyrrol $\left.{ }^{+}\right]$} & -2.80 \\
\hline 1,1-butylmethylpyrrolidinium & {$\left[\right.$ bmpyrrol $\left.^{+}\right]$} & -2.82 \\
\hline 1,1-ethylmethylpiperidinium & {$\left[\mathrm{empip}^{+}\right]$} & -2.75 \\
\hline 1,1-butylmethylpiperidinium & {$\left[\mathrm{bmpip}^{+}\right]$} & -2.64 \\
\hline
\end{tabular}

between the cation and anion, the absolute quantitative energy level of the LUMO of the total ionic liquid will be different from the energy level of the LUMO of the cation solely, but these energy levels should be correlated. To test the existence of this correlation, the LUMO energy level of several tetrafluoroborate ionic liquids and that of their cations only was calculated. Results are shown in Table 1 and Figure 3, which clearly indicate that both LUMO energy levels are correlated. The correlation coefficient is 0.99 . Therefore, the assumption that the LUMO energy level of the cation solely determines the resistance of these ionic liquids against reduction seems to be appropriate.

The energy level of the LUMO of several cations was calculated on the B3LYP level, and results are shown in Table 2. Higher LUMO energies of the cations lead to more stable ionic liquids. Therefore, from Table 2 it can be concluded that the order in resistance against reduction is piperidinium $>$ pyrrolidinium $>$ quaternary phosphonium $>$ quaternary ammonium $>$ imidazolium $>$ pyrazolium $>$ pyridinium. This order correlates to experimental data $[1,6,13]$.

The experimentally determined electrochemical window of several ionic liquids with tetrafluoroborate and trifluoro methylsulfonate anions was thereafter correlated to the LUMO energy level of the cation. When the anion type is fixed, the width of the electrochemical window will only 

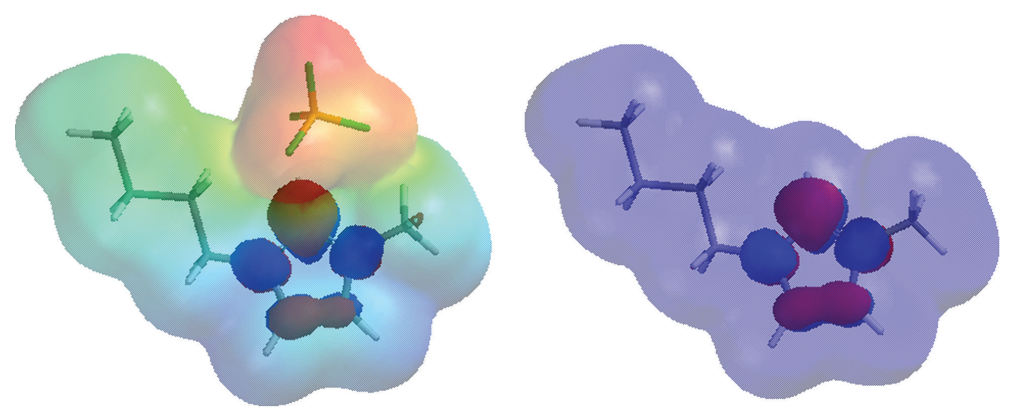

FIgURE 2: Structures of $\left[\mathrm{bmim}^{+}\right]\left[\mathrm{BF}_{4}^{-}\right]$and $\left[\mathrm{bmim}^{+}\right]$cation, showing the electrostatic potential projected on the van der Waals surface ( surface $=$ electron density of $0.002 \mathrm{e}^{\mathrm{au}}{ }^{3}$, property $=$ electrostatic potential) and the position of the LUMO on $\left[\mathrm{bmim}^{+}\right]\left[\mathrm{BF}_{4}{ }^{-}\right]$and on the cation $\left[\mathrm{bmim}^{+}\right]$only. Red and blue in the orbitals refer to the phase only, and not to charge.

TABLE 3: Calculated LUMO energy (B3LYP) of the cation of several ionic liquids with the same anion and their experimentally determined electrochemical windows.

\begin{tabular}{lcccc}
\hline Cation & \multirow{2}{*}{$E_{\mathrm{LUMO}}(\mathrm{B} 3 \mathrm{LYP})[\mathrm{eV}]$} & \multicolumn{2}{c}{ Electrochemical window $[\mathrm{V}]$} & References \\
& -6.46 & Anion $=\left[\mathrm{BF}_{4}^{-}\right]$ & - & {$[1]$} \\
{$\left[\mathrm{bpyrid}^{+}\right]$} & -5.28 & 4.4 & - & {$[1]$} \\
{$\left[\mathrm{bmpyraz}^{+}\right]$} & -4.92 & 4.1 & 4.3 & {$[7,13,17,25]$} \\
{$\left[\mathrm{emim}^{+}\right]$} & -4.82 & 4.15 & 4.3 & {$[4,7,26]$} \\
{$\left[\mathrm{bmim}^{+}\right]$} & -4.65 & - & 4.4 & {$[7]$} \\
{$\left[\mathrm{edmim}^{+}\right]$} & -3.22 & - & 5.2 & {$[13]$} \\
{$\left[\mathrm{N}^{+}(1113)^{+}\right]$} & -2.82 & - & 5.5 & {$[27]$} \\
{$\left[\mathrm{bmpyrrol}^{+}\right]$} & & & & \\
\hline
\end{tabular}

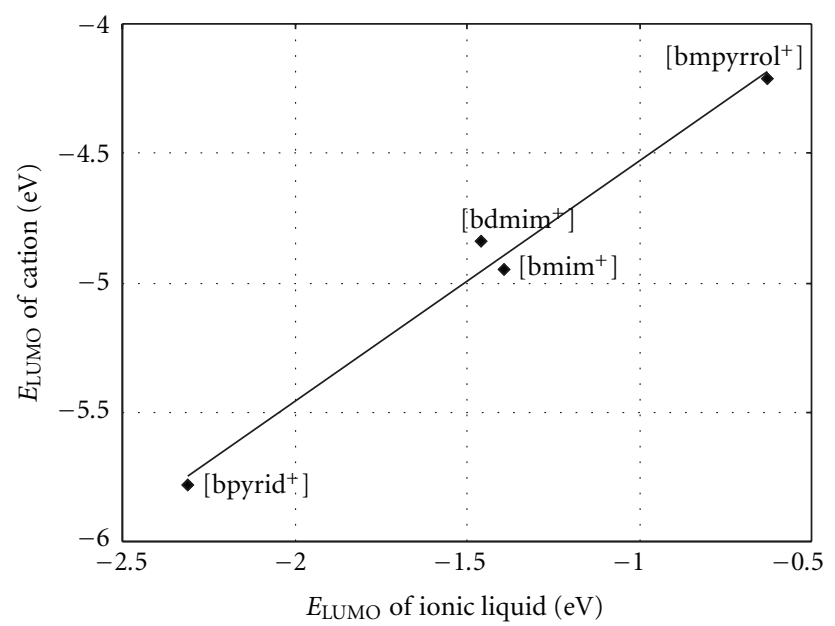

Figure 3: $E_{\mathrm{LUMO}}$ of ionic liquid $\left(\right.$ anion $\left.=\left[\mathrm{BF}_{4}^{-}\right]\right)$versus $E_{\mathrm{LUMO}}$ of cation (calculated at PM3 level). The correlation coefficient is 0.99 .

be determined by the stability of the cation with respect to reduction.

In Table 3 the calculated LUMO energy level (on B3LYP level) of the cation of several ionic liquids with the same anion and their experimentally determined electrochemical windows are given.

From Figure 4 it can be seen that the correlation is excellent with correlation coefficients of 0.98 and 0.99 and that the influence of these type of anions on the electrochemical

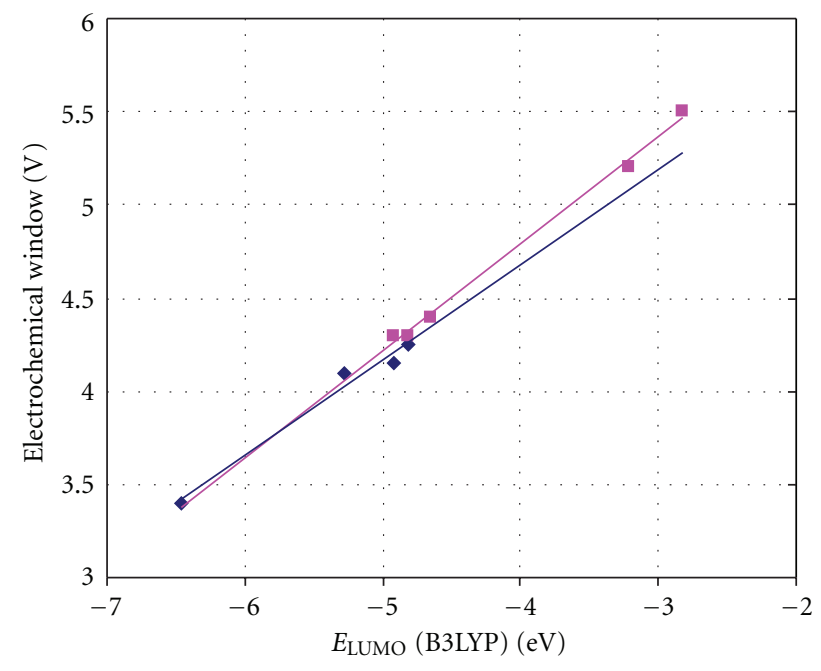

FIgure 4: Plot of calculated $E_{\text {LUMO }}$ (B3LYP method) of the cation versus electrochemical window of the ionic liquid: blue: anion $\mathrm{BF}_{4}{ }^{-}$; pink: anion $\left(\mathrm{CF}_{3} \mathrm{SO}_{2}\right)_{2} \mathrm{~N}^{-}$. The correlation coefficients are 0.98 $\left(\right.$ anion $\left.=\mathrm{BF}_{4}^{-}\right)$and $0.99\left(\right.$ anion $=\left(\left(\mathrm{CF}_{3} \mathrm{SO}_{2}\right)_{2} \mathrm{~N}^{-}\right)$.

windows is rather small. From Tables 2 and 3 some remarks should be made. Ionic liquids consisting of cations with longer alkyl side chains are more stable with respect to reduction. This is consistent with experimental observations $[4,5,24]$ but the extension of alkyl side chains also leads to a lower conductivity [24]. Therefore it does not seem practical 
TABLE 4: Comparison of calculated $E_{\mathrm{LUMO}}$ of several cations by B3LYP and PM3 calculations.

\begin{tabular}{lcr}
\hline Cation & $E_{\mathrm{LUMO}}[\mathrm{eV}](\mathrm{DFT} / \mathrm{B} 3 \mathrm{LYP})$ & $E_{\mathrm{LUMO}}[\mathrm{eV}](\mathrm{semiempirical} / \mathrm{PM} 3)$ \\
\hline 1-butylpyridinium & -6.46 & -5.78 \\
1-butyl-2-methylpyrazolium & -5.28 & -5.41 \\
1-butyl-2,3-dimethylimidazolium & -4.54 & -4.84 \\
trimethylpropylphosphonium & -2.95 & -4.51 \\
trimethylpropylammonium & -3.22 & -4.45 \\
1,1-butylmethylpyrrolidinium & -2.82 & -4.21 \\
1,1-butylmethylpiperidinium & -2.64 & -4.16 \\
\end{tabular}

TABLE 5: Calculated PM3 LUMO energy of the cation of several ionic liquids with the same anion and their experimentally determined electrochemical windows.

\begin{tabular}{|c|c|c|c|c|}
\hline \multirow{2}{*}{ Cation } & \multirow{2}{*}{$E_{\mathrm{LUMO}}(\mathrm{PM} 3)[\mathrm{eV}]$} & \multicolumn{2}{|c|}{ Electrochemical window $[\mathrm{V}]$} & \multirow{2}{*}{ References } \\
\hline & & Anion $=\left[\mathrm{BF}_{4}^{-}\right]$ & Anion $=\left[\left(\mathrm{CF}_{3} \mathrm{SO}_{2}\right)_{2} \mathrm{~N}^{-}\right]$ & \\
\hline$\left[\right.$ bpyrid $\left.^{+}\right]$ & -5.78 & 3.4 & - & {$[1]$} \\
\hline$\left[\right.$ bmpyraz $\left.^{+}\right]$ & -5.41 & 4.1 & - & {$[1]$} \\
\hline$\left[\mathrm{emim}^{+}\right]$ & -4.98 & 4.15 & 4.3 & {$[7,13,17,25]$} \\
\hline$\left[\mathrm{bmim}^{+}\right]$ & -4.95 & 4.25 & 4.3 & {$[4,7,26]$} \\
\hline$\left[\mathrm{edmim}^{+}\right]$ & -4.88 & - & 4.4 & [7] \\
\hline$\left[\mathrm{N}(1113)^{+}\right]$ & -4.45 & - & 5.2 & {$[13]$} \\
\hline$\left[\right.$ bmpyrrol $\left.^{+}\right]$ & -4.21 & - & 5.5 & [27] \\
\hline
\end{tabular}

to increase the length of the alkyl chain. Furthermore, the electrochemical stability towards reduction of the nonaromatic N-containing cations (pyrrolidinium, piperidinium, and tetraalkylammonium) is higher than that of the aromatic cations, which is also consistent with literature data $[5,6$, 13, 24-27]. Alkylation of the aromatic ring improves the electrochemical stability [24]. However, nonaromatic cations have high melting points compared to aromatic cation-based ionic liquids [6]. They need a long alkyl side chain and/or combination with the bis(trifluoromethylsulfonyl) imide anion to have a melting point lower than room temperature [6]. Finally, it can be noticed that an increasing Lewis acidity of the ionic liquid shifts the reduction potential positively (less stable with respect to reduction), which was also shown in previous experiments [7, 15, 19]. For example, the more negative reduction potential of 2-methylimidazolium cations compared to 1,3-dialkylimidazolium cations is linked to their weaker Lewis acidity [7].

So far, the LUMO energy levels of the cations are all calculated at the B3LYP level. Semiempirical calculations on the other hand are still much simpler and faster, but definitely unreliable for energetic comparisons. Because the PM3 structures were already available, it was tried to correlate the PM3 and B3LYP LUMO energies. Table 4 shows that the semiempirical results are in full record with the B3LYP results. The correlation coefficient between the semiempirical results and the B3LYP results is 0.96 (Figure 5).

Because the PM3 calculations show the same trend in LUMO energies of the cation as the B3LYP calculations, it was also tried to correlate the electrochemical window of ionic liquids with the LUMO energy at PM3 level. The results are shown in Table 5 and Figure 6.

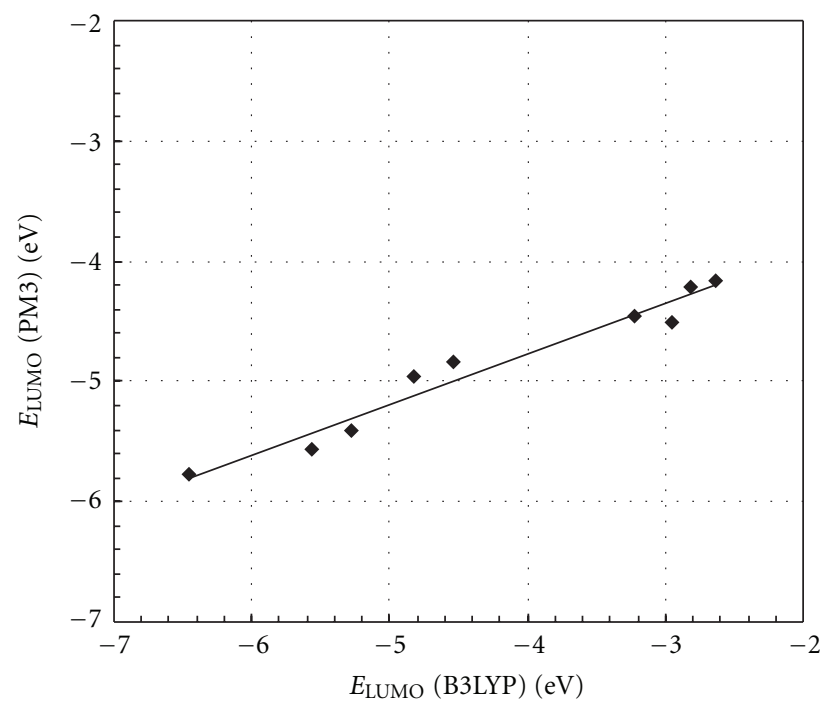

Figure 5: Comparison of calculated $E_{\text {LUMO }}$ of several cations by B3LYP and PM3 calculations. The correlation coefficient is 0.97 .

From Figure 6 it can be seen that the correlation is good with correlation coefficients of 0.91 and 0.99 . Thus PM3 calculations have similar predictive capabilities for estimating the electrochemical window of ionic liquids as B3LYP calculations. Therefore, semiempirical calculations can very well be used to predict the electrochemical window of ionic liquids with reduction-resistant anions. 


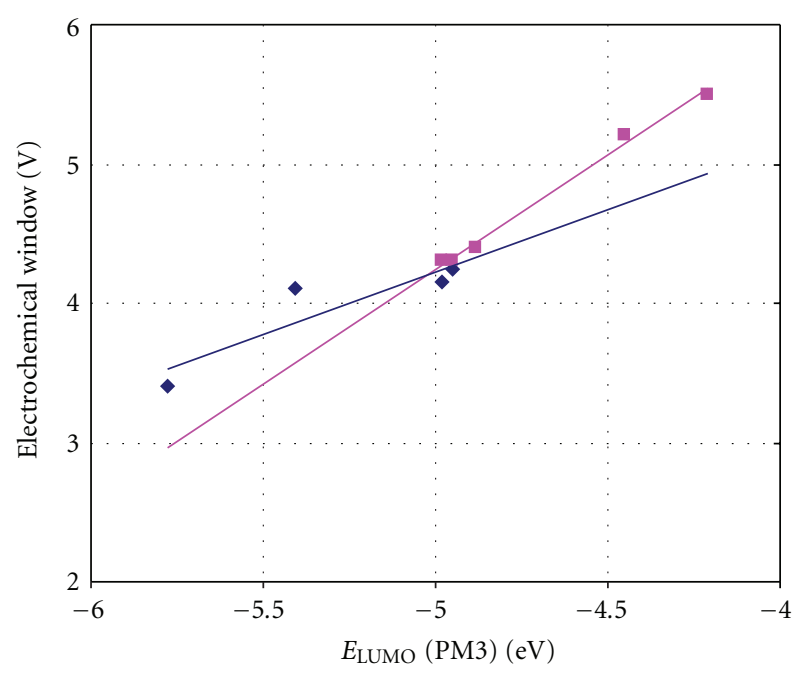

Figure 6: Plot of calculated $E_{\text {LUMO }}$ (PM3) of the cation versus electrochemical window of the ionic liquid: blue: anion $\mathrm{BF}_{4}{ }^{-}$; pink: anion $\left(\mathrm{CF}_{3} \mathrm{SO}_{2}\right)_{2} \mathrm{~N}^{-}$. The correlation coefficients are 0.91 (anion $=$ $\left.\mathrm{BF}_{4}^{-}\right)$and $0.99\left(\right.$ anion $\left.=\left(\mathrm{CF}_{3} \mathrm{SO}_{2}\right)_{2} \mathrm{~N}^{-}\right)$.

\section{Conclusions}

The LUMO of ionic liquids with reduction-resistant anions is totally located on the cation. The energy level of the LUMO of the cation is a good predictor for the width of the electrochemical window. Semiempirical PM3 calculations are in full record with B3LYP calculations; however they require very little computational resources, and thus should be preferred to predict the electrochemical window of ionic liquids. The results obtained here are another demonstration of the versatile power of the old HOMO-LUMO concept to make in principal very complicated issues understandable in rather easy way.

\section{Acknowledgments}

The authors would like to acknowledge J. van Spronsen, R. A. Penners, and M. van den Brink for their help.

\section{References}

[1] P. Wasserscheid and T. Welton, Eds., Ionic Liquids in Synthesis, Wiley-VCH, Weinheim, Germany, 2003.

[2] M. J. Earle and K. R. Seddon, "Ionic liquids. Green solvents for the future," Pure and Applied Chemistry, vol. 72, no. 7, pp. 1391-1398, 2000.

[3] J. G. Huddleston, A. E. Visser, W. M. Reichert, H. D. Willauer, G. A. Broker, and R. D. Rogers, "Characterization and comparison of hydrophilic and hydrophobic room temperature ionic liquids incorporating the imidazolium cation," Green Chemistry, vol. 3, no. 4, pp. 156-164, 2001.

[4] P. A. Z. Suarez, V. M. Selbach, J. E. L. Dullius et al., "Enlarged electrochemical window in dialkyl-imidazolium cation based room-temperature air and water-stable molten salts," Electrochimica Acta, vol. 42, no. 16, pp. 2533-2535, 1997.

[5] J. Sun, M. Forsyth, and D. R. MacFarlane, "Room-temperature molten salts based on the quaternary ammonium ion," Journal of Physical Chemistry B, vol. 102, no. 44, pp. 8858-8864, 1998.
[6] K. Matsumoto, R. Hagiwara, and Y. Ito, "Room-temperature ionic liquids with high conductivities and wide electrochemical windows $N$-Alkyl- $N$-methylpyrrolidinium and $N$-Alkyl$\mathrm{N}$ - methylpiperidinium fluorohydrogenates," Electrochemical and Solid-State Letters, vol. 7, no. 11, pp. E41-E44, 2004.

[7] P. Bonhôte, A. P. Dias, N. Papageorgiou, K. Kalyanasundaram, and M. Grätzel, "Hydrophobic, highly conductive ambienttemperature molten salts," Inorganic Chemistry, vol. 35, no. 5, pp. 1168-1178, 1996.

[8] Q. Liao, W. R. Pitner, G. Stewart, C. L. Hussey, and G. R. Stafford, "Electrodeposition of aluminum from the aluminum chloride-1-methyl-3-ethylimidazolium chloride room temperature molten salt + benzene," Journal of the Electrochemical Society, vol. 144, no. 3, pp. 936-943, 1997.

[9] J. F. Huang and I. W. Sun, "Electrodeposition of PtZn in a Lewis acidic $\mathrm{ZnCl}_{2}$-1-ethyl-3- methylimidazolium chloride ionic liquid," Electrochimica Acta, vol. 49, no. 19, pp. 32513258, 2004.

[10] P. Y. Chen, Y. F. Lin, and I. W. Sun, "Electrochemistry of gallium in the Lewis acidic aluminum chloride-1-methyl-3-ethylimidazolium chloride room-temperature molten salt," Journal of the Electrochemical Society, vol. 146, no. 9, pp. 3290-3294, 1999.

[11] W. Freyland, C. A. Zell, S. Zein El Abedin, and F. Endres, "Nanoscale electrodeposition of metals and semiconductors from ionic liquids," Electrochimica Acta, vol. 48, no. 20-22, pp. 3053-3061, 2003.

[12] R. Hagiwara and Y. Ito, "Room temperature ionic liquids of alkylimidazolium cations and fluoroanions," Journal of Fluorine Chemistry, vol. 105, no. 2, pp. 221-227, 2000.

[13] H. Sakaebe and H. Matsumoto, "N-methyl- $N$-propylpiperidinium bis(trifluoromethanesulfonyl)imide (PP13-TFSI) novel electrolyte base for Li battery," Electrochemistry Communications, vol. 5, no. 7, pp. 594-598, 2003.

[14] N. Papageorgiou, Y. Athanassov, M. Armand et al., "The performance and stability of ambient temperature molten salts for solar cell applications," Journal of the Electrochemical Society, vol. 143, no. 10, pp. 3099-3108, 1996.

[15] A. B. McEwen, H. L. Ngo, K. LeCompte, and J. L. Goldman, "Electrochemical properties of imidazolium salt electrolytes for electrochemical capacitor applications," Journal of the Electrochemical Society, vol. 146, no. 5, pp. 1687-1695, 1999.

[16] M. Ue, M. Takeda, A. Toriumi, A. Kominato, R. Hagiwara, and Y. Ito, "Application of low-viscosity ionic liquid to the electrolyte of double-layer capacitors," Journal of the Electrochemical Society, vol. 150, no. 4, pp. A499-A502, 2003.

[17] T. Sato, G. Masuda, and K. Takagi, "Electrochemical properties of novel ionic liquids for electric double layer capacitor applications," Electrochimica Acta, vol. 49, no. 21, pp. 3603-3611, 2004.

[18] W. J. Hehre, A Guide to Molecular Mechanics and Quantum Chemical Calculations, Wavefunction, Irvine, Calif, USA, 2003.

[19] V. R. Koch, L. A. Dominey, C. Nanjundiah, and M. J. Ondrechen, "The intrinsic anodic stability of several anions comprising solvent-free ionic liquids," Journal of the Electrochemical Society, vol. 143, no. 3, pp. 798-803, 1996.

[20] Wavefunction, Inc., 18401 Von Karman Avenue, Suite 370, Irvine, Calif, 92612, USA.

[21] IUPAC-International Union of Pure and Applied Chemistry, Compendium of Chemical Terminology, IUPAC-International Union of Pure and Applied Chemistry, 2nd edition, 1997.

[22] Z. Meng, A. Dölle, and W. R. Carper, "Gas phase model of an ionic liquid: semi-empirical and ab initio bonding and 
molecular structure," Journal of Molecular Structure, vol. 585, pp. 119-128, 2002.

[23] S. A. Katsyuba, P. J. Dyson, E. E. Vandyukova, A. V. Chernova, and A. Vidis, "Molecular structure, vibrational spectra, and hydrogen bonding of the ionic liquid 1-ethyl-3-methyl- $1 \mathrm{H}$ imidazolium tetrafluoroborate," Helvetica Chimica Acta, vol. 87, no. 10, pp. 2556-2565, 2004.

[24] S. Forsyth, J. Golding, D. R. MacFarlane, and M. Forsyth, " $N$ methyl- $N$-alkylpyrrolidinium tetrafluoroborate salts: ionic solvents and solid electrolytes," Electrochimica Acta, vol. 46, no. 10-11, pp. 1753-1757, 2001.

[25] J. Fuller, R. T. Carlin, and R. A. Osteryoung, "The room temperature ionic liquid 1-ethyl-3-methylimidazolium tetrafluoroborate: electrochemical couples and physical properties," Journal of the Electrochemical Society, vol. 144, no. 11, pp. 3881-3886, 1997.

[26] U. Schröder, J. D. Wadhawan, R. G. Compton et al., "Waterinduced accelerated ion diffusion: voltammetric studies in 1methyl-3-[2,6-(S)-dimethylocten-2-yl]imidazolium tetrafluoroborate, 1-butyl-3-methylimidazolium tetrafluoroborate and hexafluorophosphate ionic liquids," The New Journal of Chemistry, vol. 24, no. 12, pp. 1009-1015, 2000.

[27] D. R. MacFarlane, P. Meakin, J. Sun, N. Amini, and M. Forsyth, "Pyrrolidinium imides: a new family of molten salts and conductive plastic crystal phases," Journal of Physical Chemistry B, vol. 103, no. 20, pp. 4164-4170, 1999. 


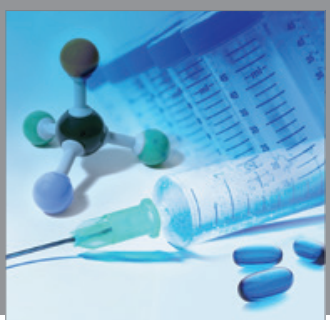

International Journal of

Medicinal Chemistry

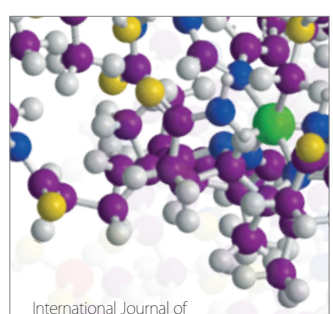

Carbohydrate Chemistry

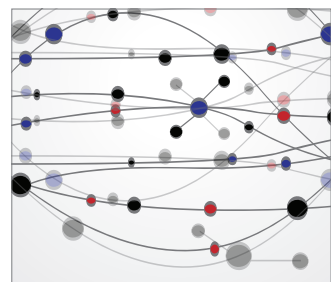

The Scientific World Journal
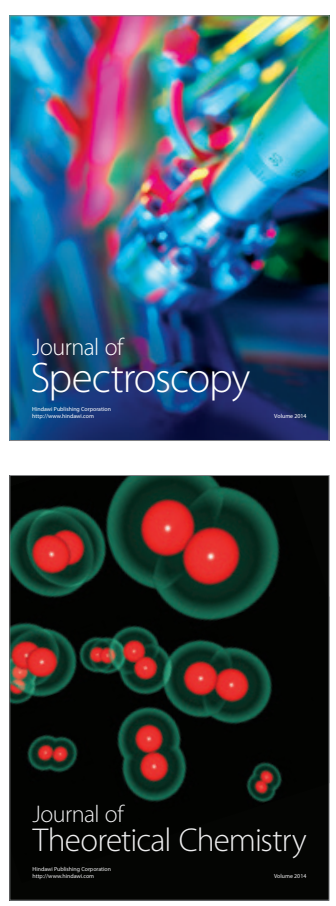
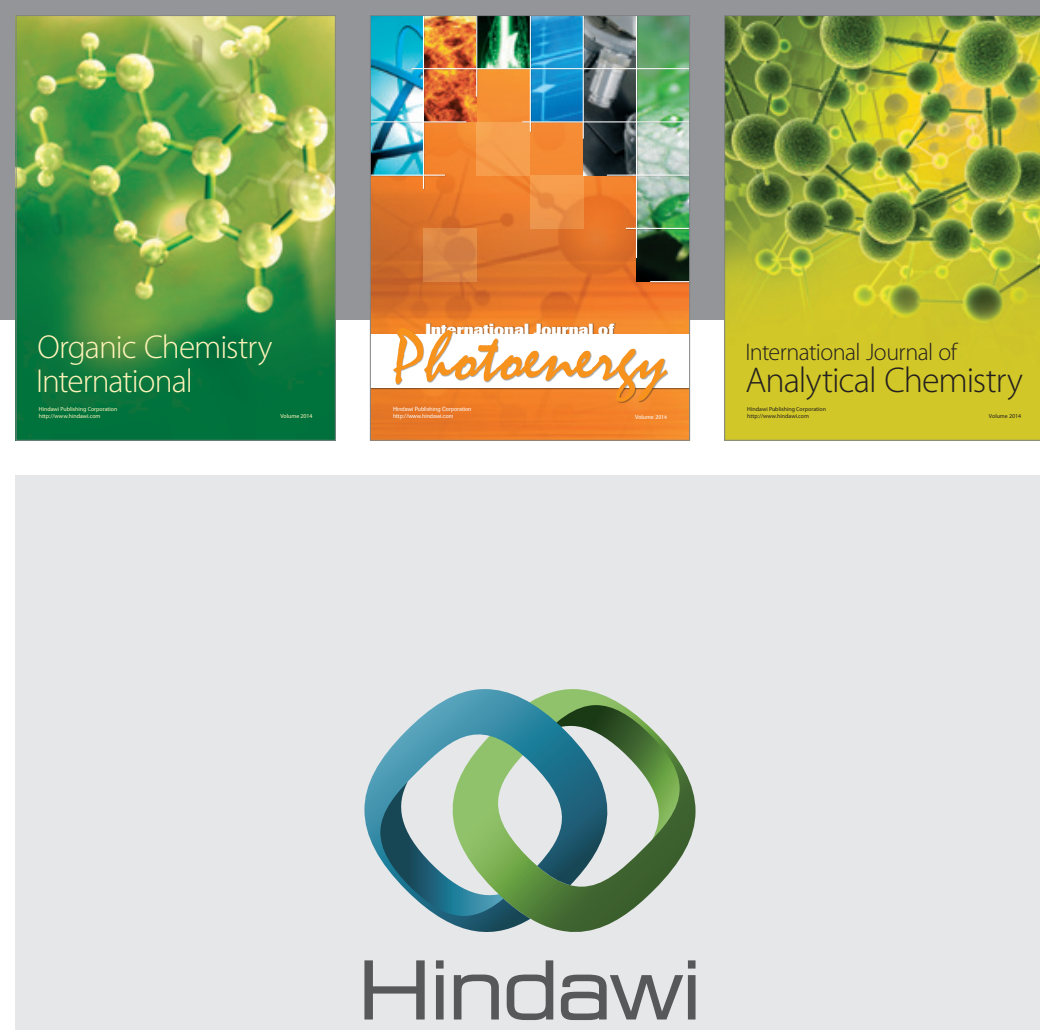

Submit your manuscripts at

http://www.hindawi.com
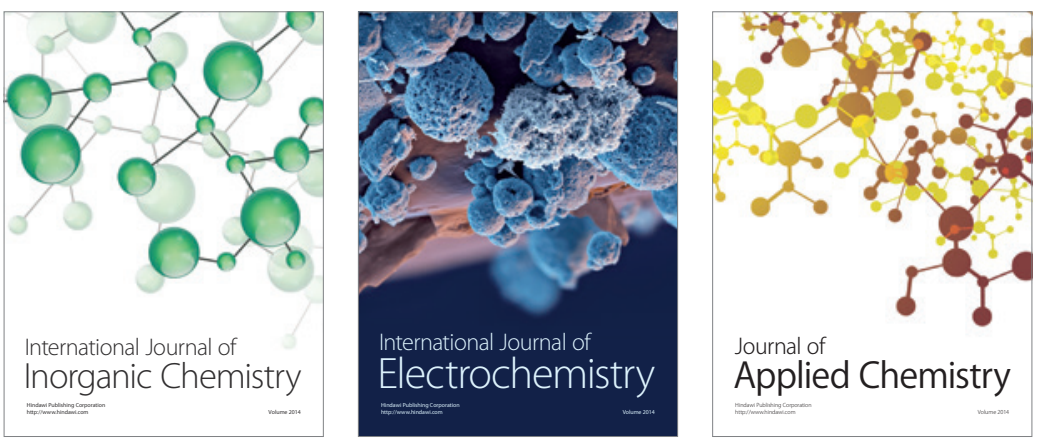

Journal of

Applied Chemistry
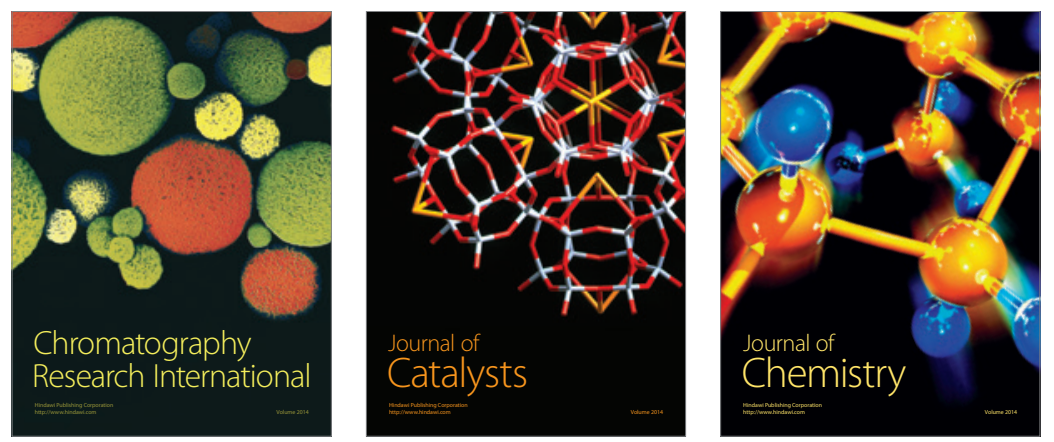
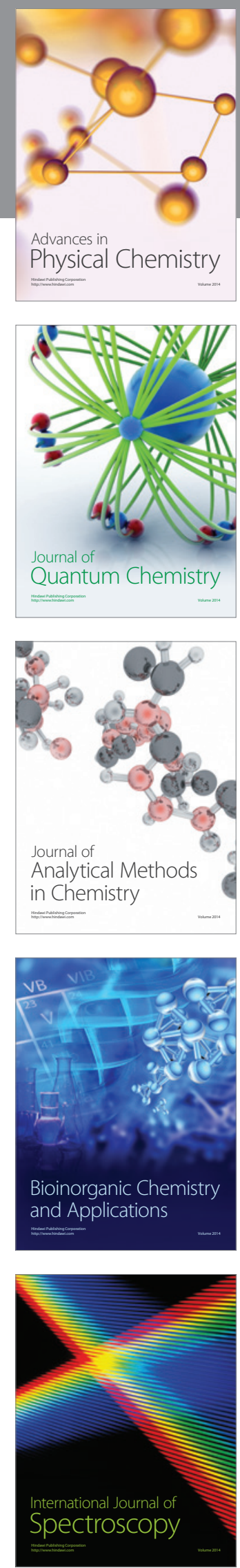